\title{
RETRACTED ARTICLE: An offline space division multiplexing based elastic optical network model with modulation format adaptation and flexible spectrum and spatial assignment
}

\author{
Sridhar lyer ${ }^{1}$ (D)
}

Received: 18 May 2018 / Accepted: 30 October 2018 / Published online: 23 November 2018

(c) China Computer Federation (CCF) 2018

The journal editors have retracted this article [1] because the article contains sections that substantially overlap with the following article [2]. The author does not agree to the retraction.

[1] Sridhar Iyer. An offline space division multiplexing based elastic optical network model with modulation format adaptation and flexible spectrum and spatial assignment. CCF Trans. Netw. (2018). https://doi.org/10.1007/s4204 5-018-0007-9.
[2] Yaghubi-Namaad et al., Adaptive Modulation and Flexible Resource Allocation in Space-Division-Multiplexed Elastic Optical Networks. Journal of Optical Communications and Networking, Volume 10, No 3, March 2018.

The online version of this article contains the full text of the retracted article as electronic supplementary material.

Electronic supplementary material The online version of this article (https://doi.org/10.1007/s42045-018-0007-9) contains supplementary material, which is available to authorized users.

Sridhar Iyer

sridhariyer1983@gmail.com

1 Department of ECE, Jain College of Engineering, T.S.

Nagar, Hunchanatti Cross, Belagavi, Karnataka 590014,

India 